\title{
Variability of the chronic obstructive pulmonary disease key epidemiological data in Europe: systematic review
}

\author{
Kokuvi Atsou ${ }^{1,2^{*}}$, Christos Chouaid ${ }^{1,2,3}$, Gilles Hejblum ${ }^{1,2,4}$
}

\begin{abstract}
Background: Chronic obstructive pulmonary disease (COPD) is predicted to become a major cause of death worldwide. Studies on the variability in the estimates of key epidemiological parameters of COPD may contribute to better assessment of the burden of this disease and to helpful guidance for future research and public policies. In the present study, we examined differences in the main epidemiological characteristics of COPD derived from studies across countries of the European Union, focusing on prevalence, severity, frequency of exacerbations and mortality, as well as on differences between the studies' methods.

Methods: This systematic review was based on a search for the relevant literature in the Science Citation Index database via the Web of Science and on COPD mortality rates issued from national statistics. Analysis was finally based on 65 articles and Eurostat COPD mortality data for 21 European countries.

Results: Epidemiological characteristics of COPD varied widely from country to country. For example, prevalence estimates ranged between $2.1 \%$ and $26.1 \%$, depending on the country, the age group and the methods used. Likewise, COPD mortality rates ranged from 7.2 to 36.1 per $10^{5}$ inhabitants. The methods used to estimate these epidemiological parameters were highly variable in terms of the definition of COPD, severity scales, methods of investigation and target populations. Nevertheless, to a large extent, several recent international guidelines or research initiatives, such as GOLD, BOLD or PLATINO, have boosted a substantial standardization of methodology in data collection and have resulted in the availability of more comparable epidemiological estimates across countries. On the basis of such standardization, severity estimates as well as prevalence estimates present much less variation across countries. The contribution of these recent guidelines and initiatives is outlined, as are the problems remaining in arriving at more accurate COPD epidemiological estimates across European countries.

Conclusions: The accuracy of COPD epidemiological parameters is important for guiding decision making with regard to preventive measures, interventions and patient management in various health care systems. Therefore, the recent initiatives for standardizing data collection should be enhanced to result in COPD epidemiological estimates of improved quality. Moreover, establishing international guidelines for reporting research on COPD may also constitute a major contribution.
\end{abstract}

\section{Background}

Chronic obstructive pulmonary disease (COPD) is a preventable disease characterized by partially irreversible airflow limitation due to progressive inflammation of the lower airways. Smoking is the main risk factor $[1,2]$. COPD is a common disease whose age-standardized

\footnotetext{
* Correspondence: kokuvi.atsou@u707.jussieu.fr

${ }^{1}$ INSERM, U707, F-75012 Paris, France

Full list of author information is available at the end of the article
}

mortality rate increased during the 1990 s, and it is predicted to be a major cause of death worldwide during the next two decades [3-5]. With such a high burden on the healthcare system, emphasis on better diagnosis and management of the disease must be achieved and reliable epidemiological data on the prevalence and severity of COPD and its exacerbations are crucial to guide decisions. Indeed, international comparisons of COPD prevalence, mortality rates and management of acute exacerbations

\section{(Ciomed Central}

(C) 2011 Atsou et al; licensee BioMed Central Ltd. This is an Open Access article distributed under the terms of the Creative Commons Attribution License (http://creativecommons.org/licenses/by/2.0), which permits unrestricted use, distribution, and reproduction in any medium, provided the original work is properly cited. 
may help to identify the most effective healthcare systems in this setting.

Differences in healthcare systems and criteria make it difficult to compare data across different countries [6,7]. Efforts have been made to standardize prevalence estimates through the international Latin American Project for the Investigation of Obstructive Lung Disease (PLATINO) and Burden of Obstructive Lung Disease (BOLD) study initiatives, for example [8,9]. To obtain a representative picture of the epidemiological situation in Europe and what has been achieved so far, we reviewed the literature on COPD in Europe, focusing on prevalence, severity, exacerbations and mortality. The goal of the study was to examine the differences in these epidemiological estimates across countries in light of the differences in methods used from one study to another. Therefore, we collected the following features associated with the epidemiological estimates reported: publication date, type of population, sample size and definitions used (for example, severity scale used, exacerbation definition used). This review strongly suggests that establishing reporting guidelines dedicated to COPD studies may constitute a major contribution to enhancing the value of COPD research and management by facilitating comparisons between studies.

\section{Methods}

\section{Document search}

We sought documents on the prevalence, mortality, severity and exacerbations of COPD in the Science Citation Index database via the Web of Science (WOS) (Thomson Reuters, New York, NY, USA). The search was limited to documents published between 1991 and 2009, focusing on the epidemiology of COPD (prevalence, severity, exacerbations and mortality) in different populations (general population, patients followed up by a general practitioner and/or chest specialist, ambulatory patients and inpatients). We also extracted data from the European statistical database (Eurostat) [10].

WOS was queried using a four-step strategy as follows:

1. $\mathrm{TS}=\mathrm{COPD}$ or chronic obstructive pulmonary disease or chronic bronchitis

2. TS $=$ Prevalence or severity or mortality or exacerbation

3. $\mathrm{TI}=$ Cancer

4. (2 AND 1) NOT 3

where TI is a term search limited to the title of the document and TS is a term search in the title, abstract and keywords.

\section{Document triage and selection}

We applied the following exclusion criteria to the WOS documents obtained using the above strategy: We excluded documents concerning non-European Union countries, documents that were not original articles or reviews and documents with WOS subject categories not relevant to this study (for example, biophysics, biochemistry, microbiology, psychology, social issues, bioinformatics, toxicology). Finally, document eligibility was completed by deeper examination of the remaining articles. Articles not dealing primarily with the epidemiology of COPD (that is, prevalence, severity, mortality, exacerbations) or not specifying sufficiently important definitions related to the epidemiological estimates (for example, diagnostic tests used and target population, including inclusion and exclusion criteria) were excluded from the review. A comparable search in the MEDLINE database via the PubMed interface did not retrieve any additional documents.

The Eurostat database was used to extract age-standardized COPD mortality rates (deaths per 100,000 inhabitants) for 2007 by using code J40-47 (death as a result of lower respiratory tract disease) and by excluding codes J45 and J46 (death as a result of asthma). Death as a result of bronchiectasis (J47) was not excluded, because the corresponding number of cases was considered minor.

\section{Analysis of the collected information}

Considering each of the reported epidemiological estimates (prevalence, severity, exacerbations and mortality), we collected several associated features: publication date, type of population under study, sample size and definitions used (for example, severity scale used, exacerbation definition used). We then listed each estimate report with its associated feature described above to obtain a picture of the variability of estimates across countries in light of the methodological differences between studies.

\section{Results}

\section{Information included in the review}

The process for including final information used in the review is detailed in Figure 1. The initial literature search resulted in 7,302 WOS documents, and after applying the exclusion criteria and eligibility steps, 65 articles (61 in English, 3 in Spanish [11-13] and 1 in French [14]) were finally included in the study (Figure 1). COPD mortality data in the Eurostat database were available for 21 countries of the European Union.

\section{Prevalence}

COPD prevalence data can be categorized into four types according to the criteria used to define the disease (Table 1; see also a graph of these data in Additional file 1, Figure A1), namely, symptoms [15-17], physician reports [18-23], spirometry [8,11-13,24-39] and models [40-42]. 


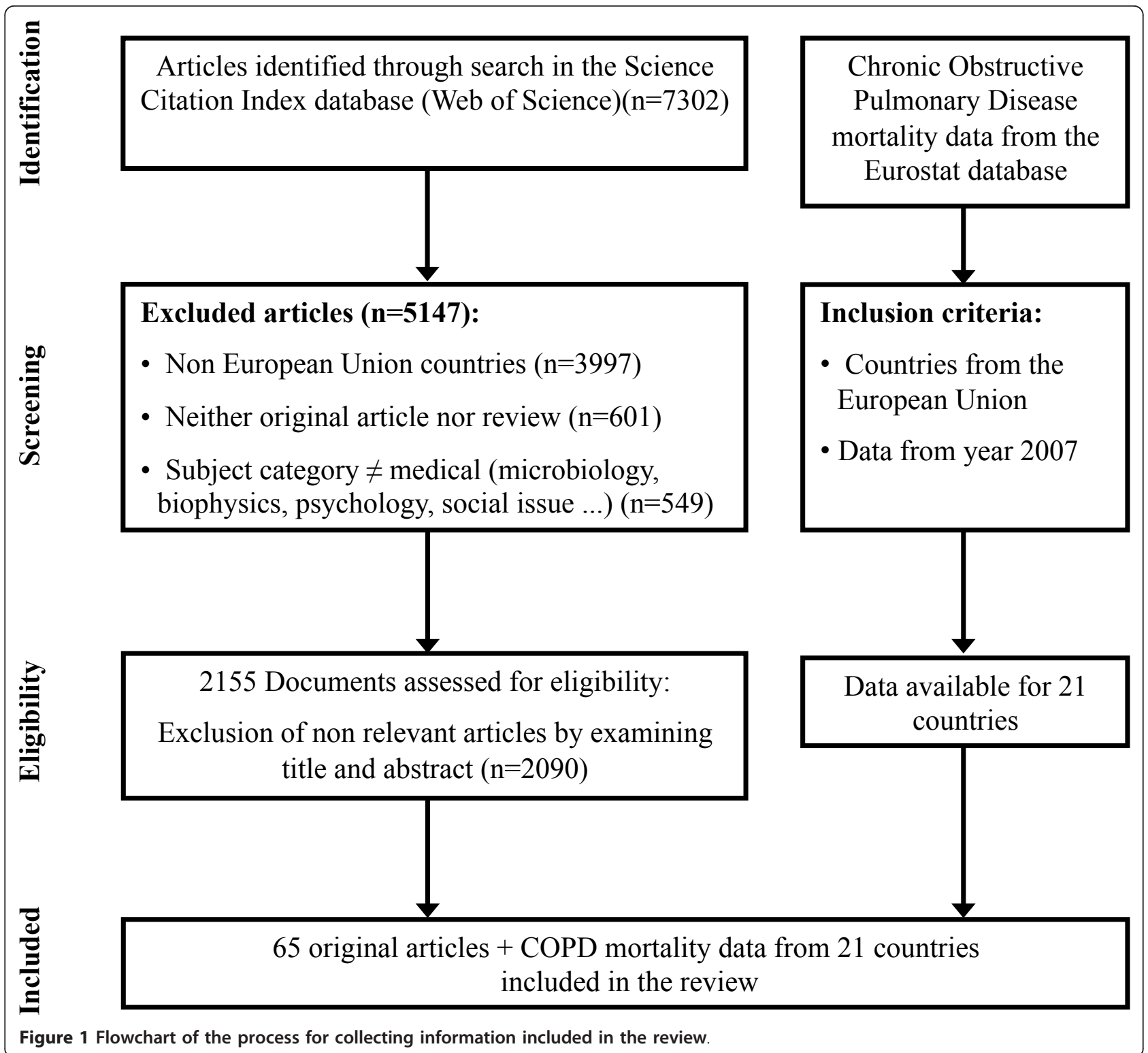

Surveys based on symptoms (cough and expectoration on most days for as much as three months per year and for at least two successive years) were used to estimate the prevalence of chronic bronchitis (initial stage of COPD). This prevalence ranged from $2.6 \%$ to $9.5 \%$ in adults under 44 years of age [15-17]. Major variability was noted across European countries, with prevalence rates ranging from $0.7 \%$ to $9.7 \%$ (median, $2.6 \%$ ) in a study covering 16 countries [17]. There were also significant regional differences within a given country [17]. The prevalence of chronic bronchitis is reported to be significantly lower among women than among men in all countries $(2.8 \%$ versus $3.7 \%$; $P<0.001)$ [17]. The prevalence increased gradually from nonsmokers to "moderate-heavy" smokers ( $\geq 15$ packs-yrs) and from higher socioeconomic classes to the unemployed and blue-collar workers [15-17].

Studies [18-23] based on diagnoses of chronic bronchitis by healthcare professionals have produced less varying results, with prevalence rates ranging from $3.7 \%$ to $5.6 \%$ among adults. In studies based on respiratory function, such as the ratio of the maximum expiratory volume in 1 second $\left(\mathrm{FEV}_{1}\right)$ over forced vital capacity [8,11-13,24-39] or the difference between measured and predicted $\mathrm{FEV}_{1}$ [37], the prevalence ranged from $2.1 \%$ [37] to $26.1 \%$ $[8,19]$, but this large range may be attributed in part to the different types of population in which the prevalence was estimated. However, differences in population characteristics only partly explain the variability of the reported prevalence estimates. Even if one limits the 
Table 1 COPD prevalence data ${ }^{a}$

\begin{tabular}{|c|c|c|c|c|}
\hline Criteria used to define COPD & Country (sample size) & Study population & Age $^{b}(y r)$ & Prevalence (\%) \\
\hline \multicolumn{5}{|l|}{ Symptoms ${ }^{c}$} \\
\hline Cerveri et al., 2003 [15] & Italy $(18,645)$ & General population & $20-44$ & 9.5 \\
\hline Huchon et al., 2002 [16] & France $(14,076)$ & General population & $\geq 25$ & 4.1 \\
\hline Cerveri et al., 2001 [17] & 16 countries $(14,819)$ & General population & $20-44$ & 2.6 \\
\hline \multicolumn{5}{|l|}{ Physician reports } \\
\hline Cazzola et al., 2009 [18] & Italy $(15,229)$ & General population & NS & 2.5 \\
\hline Schirnhofer et al., 2007 [19] & Austria $(1,258)$ & General population & $\geq 40$ & 5.6 \\
\hline Montnemery et al., 2006 [20] & Sweden $(3,692)$ & General population & $20-59$ & 3.6 \\
\hline Hedman et al., 1999 [21] & Finland $(3,102)$ & General population & $18-65$ & 3.7 \\
\hline Montnemery et al., 1998 [22] & Sweden $(8,469)$ & General population & $20-59$ & 4.6 \\
\hline Lundback et al., 1991 [23] & Sweden $(6,610)$ & General population & $35-66$ & 4.1 \\
\hline
\end{tabular}

Functional respiratory tests

Miravitlles et al., 2009 [24]

Van Durme et al., 2009 [25]

Hansen et al., 2008 [26]

Bednarek et al., 2008 [27]

Roche et al., 2008 [28]

Buist et al., 2007 [8]

Shahab et al., 2006 [29]

Stavem et al., 2006 [30]

Sichletidis et al., 2005 [31]

Murtagh et al., 2005 [32]

Tzanakis et al., 2004 [33]

Hasselgren et al., 2001 [34]

Peña et al., 2000 [35]

Viegi et al., 2000 [36]

Jaen et al., 1999 [11]

Dickinson et al., 1999 [37]

Marco Jordán et al., 1998 [12]

Renwick \& Connolly, 1996 [38]

Brotons et al., 1994 [13]

Bakke et al., 1991 [39]

Models

$$
\text { Peabody et al., } 2005 \text { [40] }
$$

Feenstra et al., 2001 [41]

Stang et al., 2000 [42]

Spain $(4,274)$
Netherlands $(7,983)$
Denmark $(4,757)$
Poland $(1,960)$
France $(4,764)$
Austria $(1,258)$
Germany $(683)$
Poland $(526)$
Norway $(638)$
United Kingdom $(8,215)$
Norway $(1,619)$
Greece $(6,112)$
Ireland $(2,484)$
Greece $(888)$
Sweden $(4,814)$
Spain $(3,978)$
Italy $(1,727)$
Spain $(497)$
United Kingdom (353)
Spain $(460)$
United Kingdom (783)
Spain $(642)$
Norway $(1,275)$

Spain

Norway

Poland

Netherlands

Spain

Italy

France

United Kingdom

$\begin{array}{lll}\text { General population } & 56.6(10.7) & 10.2 \\ \text { General population } & \geq 55 & 11.6 \\ \text { General population } & 45-84 & 12.0 \\ \text { Primary care } & 56.7(11.6) & 9.3 \\ \text { Health prevention center } & 59.9(10.1) & 2.6 \\ \text { General population } & \geq 40 & 26.1^{\mathrm{d}} \\ & & 13.3 \\ & & 22.1 \\ \text { General population } & 55.5(13.5) & 18.8 \\ \text { Occupational cohort } & 49.8(5.5) & 13.3 \\ \text { General population } & 21-80 & 16.4 \\ \text { General population } & 53.3(8.6) & 5.6 \\ \text { General population } & \geq 35 & 8.3 \\ \text { General population } & 43(14.8) & 2.1 \\ \text { General population } & 40-69 & 9.1 \\ \text { General population } & \geq 25 & 11.0 \text { or } 18.3 \\ \text { General population } & 20-70 & 7.2 \\ \text { General population } & 68.25 & 9.9 \\ \text { General population } & 40-60 & 6.8 \\ \text { General practitioner } & 66.1 & 9.0 \\ \text { General population } & 35-65 & 6.4 \\ \text { General population } & 42(16.1) & 4.5 \\ & & \end{array}$

Total population

$\geq 30$

6.2

6.3

6.7

Total population $\quad \geq 20 \quad 1.5$

Total population $\quad \geq 45 \quad 10.3$

11.1

10.4

15.0

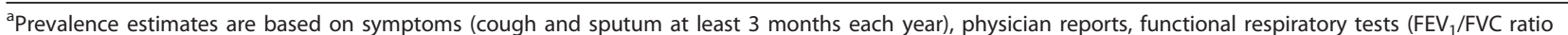
$<70 \%, \mathrm{FEV}_{1}<80 \%$ of predicted, $\mathrm{FEV}_{1} / \mathrm{FVC}$ ratio $<65 \%$, $\mathrm{FEV}_{1} / \mathrm{FVC}$ ratio $<70 \%$ or $\mathrm{FEV}_{1} / \mathrm{FVC}$ ratio $<88 \%$ (male) $/ 89 \%$ (female)) and models (general population). ${ }^{\mathrm{b}} \mathrm{Age}$ was reported in various ways distinguished here as follows: " $\geq x$ ", minimum age; " $x$ " or " $x(y)$ ", mean age or mean age (SD); " $x-y$ ", age range i.e. min-max. 'These patients had chronic bronchitis. ${ }^{\mathrm{d}}$ These data are also reported in Schirnhofer et al., 2007 [19]. Abbreviations used: COPD, chronic obstructive pulmonary disease; NS, not specified; $F_{1}$, maximum expiratory volume in 1 second; FVC, forced vital capacity. 
analysis to patients over 40 years of age, the prevalence of the COPD still varies widely, from $4.5 \%$ in Norway [39] to $26.1 \%$ in Austria [8]. The functional criteria used to diagnose COPD also vary from one study to another, depending on the classification used: American Thoracic Society (ATS) [43], British Thoracic Society (BTS) [44], European Respiratory Society Task Force (ERS) [45], or Global Initiative for Chronic Obstructive Lung Diseases (GOLD) [46]. In the international BOLD study [8], based on the general population and on the current GOLD guidelines, the prevalence estimates issued from the 12 countries under study significantly varied from one site to another, with differences between men and women likely to reflect gender smoking rates. Considering the sites from the five European countries participating in the BOLD study, prevalence estimates ranged from $13.3 \%$ in Germany to $26.1 \%$ in Austria. In all, six of the nine papers that used the definition of COPD proposed by the GOLD initiative refer to the general population $[8,19,24-26,29]$, and with respect to these data, the prevalence estimates range between $10.2 \%$ in Spain [24] and 26.1\% in Austria [8].

Several authors have proposed model-based approaches for estimating COPD prevalence [40-42]. These models combine demographic data with smoking rates [40-42], data on respiratory function in the general population $[40,42]$ and other risk factors such as air pollution and low socioeconomic status [40]. In these studies, the prevalence varied from $1.5 \%$ to $15 \%$ in the general population, and a given model [42] applied to the population over 45 years of age in four European countries resulted in estimates varying from $10.3 \%$ in Spain to $15 \%$ in the United Kingdom.

\section{Severity}

The reported epidemiology of COPD severity $[8,14,27$, 29,33,36,47-57] depends on whether the analysis concerns the general population $[8,29,33,36,47-50]$, patient follow-up by a general practitioner and/or chest specialist [14,27,51-54] or inpatients (Table 2; see also a graph of these data in Additional file 2, Figure A2) [55-57]. Moreover, results were also reported according to various severity scales (Figure 2).

In general patient populations, early-stage disease predominates among people over 40 years of age, with rates of GOLD 2006 stage 1 disease ( $\mathrm{FEV}_{1} \geq 80 \%$ of predicted) and stage 2 disease $\left(80 \%<\mathrm{FEV}_{1} \leq 50 \%\right.$ of predicted), respectively, ranging from $50.7 \%$ and $40.7 \%$ in Poland to $59.4 \%$ and $35.2 \%$ in Austria [8]. In a study based on the GOLD 2003 severity scale and on a younger population (ages 20 to 44 years), estimates substantially varied from one country to another: from $51.7 \%$ in Switzerland to $89.8 \%$ in Spain for stage 0 and from $3.4 \%$ in Italy to $16.8 \%$ in Denmark for stages 2 and 3. The authors had no clear explanation for these differences [48]. The proportion of advanced stages increases with age, peaking at age 60 years. Thus, in a Swedish study based on the BTS classification [49], the percentage of stage 4 disease, which was negligible below age 40 years, reached $22.4 \%$ at age 58 or 59 years before decreasing again to $7.3 \%$ at 73 or 74 years of age. This increase with age is observed in both men and women [8]. The relationship between tobacco consumption and GOLD stage 2 disease or higher was less clear, partly owing to interference by age [8]. Moderate forms of the disease are more frequent in cohorts of patients followed by general practitioners or specialists, with observed frequencies ranging from $27 \%$ to $56.4 \%$ [14,27,51-54].

Analyses of severity among COPD inpatients show, quite logically, more frequent advanced forms of the disease, with a dramatic decrease in the proportion of patients with mild COPD (reported proportions ranging from $0 \%$ to $7.9 \%$ ). The existence of several severity scales leads to major variations in the reported epidemiology of COPD severity, even when considering a given type of population. Depending on whether the ERS, ATS, BTS or GOLD criteria are used (Table 2), the percentage of early stages in the general population is, respectively, $80 \%, 98 \%, 65 \%$ and $55 \%$, while advanced stages represent, respectively, $95 \%, 67 \%, 85 \%$ and $58 \%$ of cases among COPD inpatients $[36,47,56]$.

In general, there is a relatively low variability in the severity estimates based on GOLD criteria and derived from a given type of population. For example, when considering the general population of patients who are at least 40 years old, the severity distributions of patients in Norway [8], Germany [8] and Sweden [47] are similar. In the same way, the severity distributions in patients recruited from general practitioners and/or specialists in Sweden [52] and Poland [27] are comparable.

\section{Exacerbations}

Tables 3 and 4 list the 22 reports mentioning the frequency of COPD exacerbations in European patients according to severity stage [53,55,58-77]. The definition of exacerbation substantially varied from one study to another (Table 3). The mean number of exacerbations per person and per year ranges from 0.6 to 3.5 [63,72] according to the disease stage and the age group (Table 4). Borg et al.'s model [77], in which parametric values were derived from the literature, used mean frequencies of exacerbations of, respectively, 0.05 and 1.47 per person per year at GOLD stages 1 and 4. According to SolerCataluña et al. [55], 26\% of very severely affected patients have at least three exacerbations per year compared to $0 \%$ of mildly affected patients. The number of exacerbations can be reduced by treatment $[60,66]$. Exacerbations are usually categorized as mild (symptoms treated at 
Table 2 Severity of COPD ${ }^{a}$

\begin{tabular}{|c|c|c|c|c|c|c|c|}
\hline \multirow[b]{2}{*}{ Study population } & \multirow[b]{2}{*}{ Country (sample size) } & \multirow[b]{2}{*}{ Criteria } & \multirow[b]{2}{*}{$\mathrm{Age}^{\mathrm{b}}(\mathrm{yr})$} & \multicolumn{4}{|c|}{ Severityc (\%) } \\
\hline & & & & Stage 1 & Stage 2 & Stage 3 & Stage 4 \\
\hline \multicolumn{8}{|l|}{ General population } \\
\hline \multirow[t]{4}{*}{ Buist et al., 2007 [8] } & Austria $(1,349)$ & GOLD 2006 & $\geq 40$ & 59.4 & 35.2 & \multicolumn{2}{|c|}{5.4} \\
\hline & Germany (713) & & & 55.3 & 38.6 & \multicolumn{2}{|c|}{6.1} \\
\hline & Poland (603) & & & 50.7 & 40.7 & \multicolumn{2}{|c|}{8.6} \\
\hline & Norway (707) & & & 55.8 & 37.8 & \multicolumn{2}{|c|}{6.4} \\
\hline Shahab et al., 2006 [29] & United Kingdom $(8,215)$ & GOLD 2006 & $55.5(13.5)$ & 41.6 & 43.9 & \multicolumn{2}{|c|}{14.5} \\
\hline \multirow[t]{2}{*}{ Lindberg et al., 2006 [47] } & Sweden $(1,237)$ & GOLD 2006 & 46-77 & 57.0 & 37.0 & 5.0 & 1.0 \\
\hline & & BTS 1997 & & 65.0 & 27.0 & 8.0 & NA \\
\hline \multirow[t]{12}{*}{ De Marco et al., 2004 [48] } & Belgium $(1,122)$ & GOLD 2003 & $20-44$ & 58.6 & \multicolumn{2}{|c|}{41.4} & ND \\
\hline & Denmark (394) & & & 56.4 & \multicolumn{2}{|c|}{43.6} & ND \\
\hline & France $(2,137)$ & & & 66.7 & \multicolumn{2}{|c|}{33.3} & ND \\
\hline & Germany $(1,983)$ & & & 64.8 & \multicolumn{2}{|c|}{35.2} & ND \\
\hline & Italy (910) & & & 69.4 & \multicolumn{2}{|c|}{30.6} & ND \\
\hline & Ireland (454) & & & 75.3 & \multicolumn{2}{|c|}{24.7} & ND \\
\hline & Netherlands $(1,362)$ & & & 74.3 & \multicolumn{2}{|c|}{25.7} & ND \\
\hline & Norway (969) & & & 40.7 & \multicolumn{2}{|c|}{59.3} & ND \\
\hline & Spain $(1,942)$ & & & 59.2 & & & ND \\
\hline & Sweden $(1,859)$ & & & 79.3 & & & ND \\
\hline & Switzerland (853) & & & 76.3 & & & ND \\
\hline & United Kingdom $(1,198)$ & & & 69.8 & & & ND \\
\hline Tzanakis et al., 2004 [33] & Greece (888) & ERS 1995 & $\geq 35$ & 58.2 & 25.6 & 16.2 & NA \\
\hline Jansson et al., 2002 [49] & Sweden (212) & BTS $^{\mathrm{e}}$ & $28-29$ & 75.0 & 25.0 & 0 & 0 \\
\hline & & & $43-44$ & 46.6 & 46.6 & 6.8 & 0 \\
\hline & & & $49-50$ & 16.0 & 64.0 & 12.0 & 8.0 \\
\hline & & & $58-59$ & 15.4 & 57.7 & 15.4 & 11.5 \\
\hline & & & $64-65$ & 6.9 & 29.3 & 41.4 & 22.4 \\
\hline & & & $73-74$ & 14.3 & 21.4 & 47.6 & 16.7 \\
\hline & & & $79-80$ & 9.8 & 34.2 & 48.8 & 7.3 \\
\hline Viegi et al., 2000 [36] & Italy $(1,727)$ & ERS 1995 & $\geq 25$ & 81.0 & 14.0 & 5.0 & NA \\
\hline & & ATS 1995 & & 98.2 & 1.8 & 0 & NA \\
\hline & & Clinical $^{f}$ & & 86.1 & & 13.9 & \\
\hline Von Hertzen et al., $2000[50]^{9}$ & Finland $(7,217)$ & & $\geq 30$ & 59.8 & 34.1 & 6.1 & NA \\
\hline General practitioner and/or chest sp & & & & & & & \\
\hline Izquierdo et al., 2009 [51] & Spain $(3,619)$ & GOLD 2006 & $67.0(10.8)$ & 20.1 & 54.0 & 22.1 & 3.8 \\
\hline Bednarek et al., 2008 [27] & Poland $(1,960)$ & GOLD 2006 & $56.7(11.6)$ & 30.6 & 51.4 & 15.3 & 2.7 \\
\hline Hoogendoorn et al., 2006 [52] & Sweden (481) & GOLD 2006 & 65.5 & 30.0 & 51.0 & 17.0 & 2.0 \\
\hline Piperno et al., 2005 [14] & France $(3,411)$ & SPLF 1996 & $58.4(9.9)$ & 31.3 & 50.2 & 18.5 & NA \\
\hline Detournay et al., 2004 [53] & France (255) & SPLF 1996 & 67.1 & 56.0 & 27.0 & 17.0 & NA \\
\hline Soriano et al., 2000 [54] & United Kingdom $(23,277)$ & Prescriptions & $66.7(15.5)$ & 35.5 & 56.4 & 8.1 & NA \\
\hline Hospital & & & & & & & \\
\hline Soler-Cataluña et al., 2005 [55] & Netherlands (304) & GOLD 2006 & $71(9)$ & 6.6 & 35.8 & 33.6 & 24.0 \\
\hline Tsoumakidou et al., 2004 [56] & Greece (67) & ERS 1995 & 69.0 & 0 & 4.5 & 95.5 & NA \\
\hline & & BTS 1997 & 69.5 & 1.5 & 14.9 & 83.6 & NA \\
\hline & & ATS 1995 & 67.6 & 4.5 & 28.3 & 67.2 & NA \\
\hline
\end{tabular}


Table 2 Severity of COPDa (Continued)

\begin{tabular}{|c|c|c|c|c|c|}
\hline & & 69.5 & 0 & 58.2 & 41.8 \\
\hline Kornmann et al., 2003 [57] & GOLD 2001 & $\{55\}$ & 7.9 & 73.0 & 19.1 \\
\hline \multicolumn{6}{|c|}{ 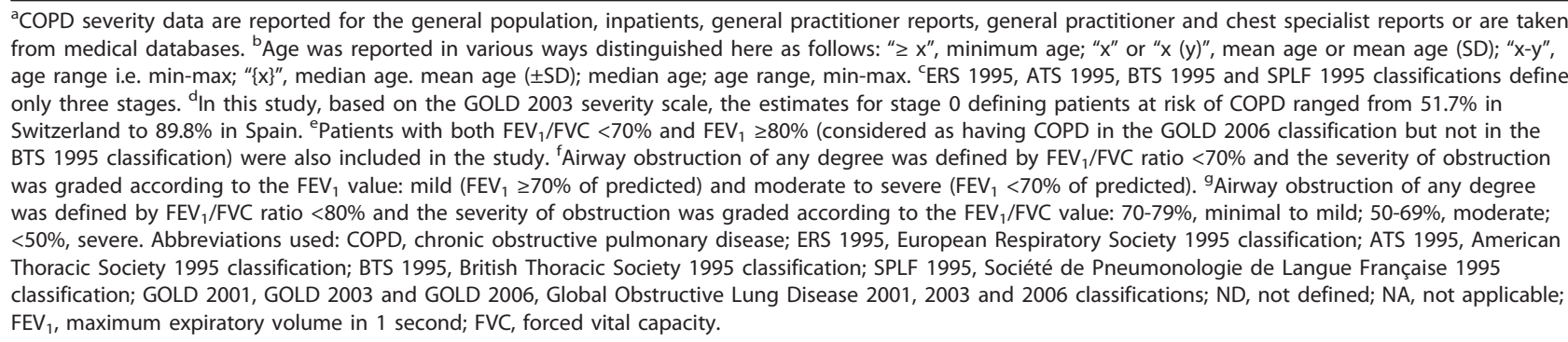 } \\
\hline
\end{tabular}

home or easily tolerated), moderate (treatment in a hospital or affecting daily activity) or severe (specialist treatment or inability to work). More severe disease stages are associated with more severe exacerbations $[60,66]$. In Borg et al.'s model [77], the average frequencies of severe exacerbations are 0.01 and 0.33 per patient per year at GOLD stage 1 and GOLD stage 4 , respectively. Such estimates have been confirmed by another observational study [55].

\section{Mortality}

As shown in Table 5 (see also a graph of these data in Additional file 3, Figure A3), reported estimates of COPD mortality in the general population vary from

\section{$\square$ undefined $\square$ mild $\square$ moderate $\square$ moderately severe $\square$ severe $\boldsymbol{\square}_{\text {very severe }}$}

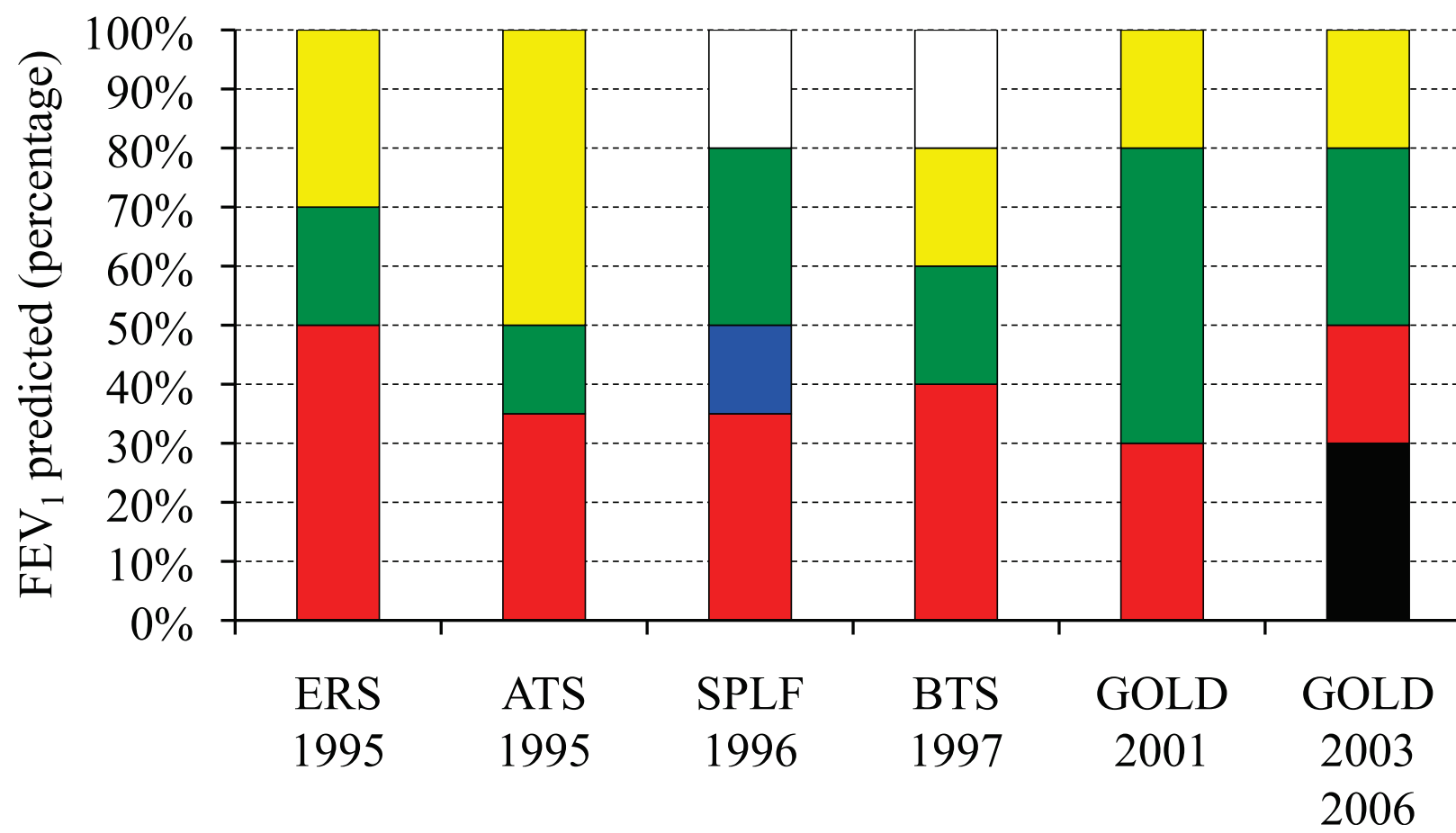

Figure 2 The most popular chronic obstructive pulmonary disease classifications: ERS, European Respiratory Society; ATS, American Thoracic Society; SPLF, Société de Pneumologie de Langue Française; BTS, British Thoracic Society; GOLD, Global Initiative for Chronic Obstructive Lung Disease; FEV $_{\mathbf{1}}$, forced expiratory volume in $\mathbf{1}$ second. ATS, BTS, ERS and SPLF classifications define three stages of severity between $0 \%$ and 100\% (ATS and ERS) or 80\% (BTS and SPLF) of predicted FEV 1 . The most recent classification is the GOLD classification, which was initially proposed in 2001 and has been modified twice, in 2003 and 2006. In 2003, the GOLD classification evolved from three to four stages plus a supplementary stage 0 defining patients at risk (that is, the presence of chronic cough and sputum, but no obstruction together with FEV ${ }_{1}$ over forced vital capacity ratio $>70 \%$; stage 0 is not shown in the figure), and stage 0 was not kept in the GOLD classification system in 2006. 
Table 3 Exacerbation definitions ${ }^{a}$

\begin{tabular}{|c|c|}
\hline Diagnostic method & Description of symptoms \\
\hline \multicolumn{2}{|l|}{ Treatment } \\
\hline Burge et al., $2003[58]^{\mathrm{b}}$ & $\begin{array}{l}\text { Chest problem requiring treatment with oral corticosteroids and/or antibiotics as defined by the treating } \\
\text { physician }\end{array}$ \\
\hline Calverley et al., 2003 [59] & Worsening of COPD symptoms that required treatment with antibiotics, oral corticosteroids or both \\
\hline Jones et al., $2003[60]^{b}$ & Chest problems requiring treatment with antibiotics and/or oral corticosteroids \\
\hline Andersson et al., 2002 [61] & $\begin{array}{l}\text { Increased dose of current treatment and/or treatment with antibiotics or systemic corticosteroids and/or general } \\
\text { practitioner or outpatient visit or hospital admission }\end{array}$ \\
\hline Burge et al., $2000[62]^{\mathrm{b}}$ & $\begin{array}{l}\text { Worsening of respiratory symptoms that required treatment with oral corticosteroids, antibiotics or both as } \\
\text { judged by the general practitioner }\end{array}$ \\
\hline
\end{tabular}

Symptoms

Effing et al., 2009 [63] Presence for at least 2 consecutive days of an increase in any two major symptoms or an increase in one major and one minor symptom

Worth et al., 2009 [64] A complex of at least two respiratory adverse events with a duration of more than 3 days

Schermer et al., 2009 [65] Episode with one or more subsequent unscheduled contacts with either a general practitioner or a chest physician because of worsening of respiratory symptoms

O'Reilly et al., $2006[66]^{c}$ Symptom-based: Symptom score of at least 2 for 2 consecutive days with no score for at least two of these symptoms in the previous 5 days Healthcare-based: Need to take antibiotics and/or oral corticosteroids for chest problem

Wilkinson et al., 2006 [67] Not defined but specified as symptom-based

Donaldson et al., 2003 [68] An increase in either two or more major symptoms or any one major symptom plus any minor symptoms occurring on 2 or more consecutive days

Seemungal et al., 2000 [69] Presence for at least 2 consecutive days of an increase in any two major symptoms or an increase in one major and one minor symptom

Treatment and symptoms

Seemungal et al., 2008 [70] Sustained worsening of baseline respiratory symptoms for at least 2 days that required treatment with oral corticosteroids and/or antibiotics

Tashkin et al., 2008 [71] Increase or new onset of more than one respiratory symptom (cough, sputum, sputum purulence, wheezing or dyspnea) lasting 3 days or more and requiring treatment with an antibiotic or a systemic corticosteroid

Calverley et al., 2008 [72] Clinically significant worsening of COPD symptoms requiring treatment with antibiotics and/or systemic steroids

Wedzicha et al., 2008 [73] Symptom worsening that required treatment with oral corticosteroids and/or antibiotics or required hospitalization

Dusser et al., 2006 [74]

Onset of at least one clinical descriptor (worsening of dyspnea, cough or sputum production, appearance of purulent sputum, fever $\left(>38^{\circ} \mathrm{C}\right.$ ), appearance of a new chest radiograph abnormality) lasting $\geq 2$ days and requiring a new prescription or an increase in the dose of $\beta_{2}$-agonists, antibiotics, corticosteroids or bronchodilators

Soler-Cataluña et al., 2005 [55]

Sustained increase in respiratory symptomatology compared with baseline requiring modification of regular medication and hospital treatment (acute exacerbation of COPD)

Oostenbrink et al., 2004 [75] Complex of respiratory symptoms (new onset or worsening of more than one symptom such as cough, sputum, dyspnea or wheeze) lasting for $\geq 3$ days

Brusasco et al., 2003 [76] Complex of respiratory symptoms (new onset or an increase in at least one of the following: cough, sputum, dyspnea, wheeze, chest discomfort) lasting at least 3 days and usually associated with therapeutic intervention

Model

Borg et al., 2004 [77]

Not defined

Detournay et al., 2004 [53]

Increase in any two major symptoms (dyspnea, sputum purulence, sputum amount) or an increase in one major and one minor symptom (wheeze, sore throat, cough, and symptoms of a common cold, which were nasal congestion and/or discharge) for at least 2 consecutive days

${ }^{a}$ Criteria used to define exacerbations were symptoms, treatment, symptoms and treatment or model-based. COPD stages are defined according to GOLD [53,55,59-62,66-69,74-77,90], BTS [61] and SPLF [53] criteria. ' ${ }^{\mathrm{b}}$ These three articles concern the same patients (the Inhaled Steroids in Obstructive Lung Disease trial). 'Healthcare-based definition of exacerbation corresponds to the "treatment and symptoms"-based definition. Abbreviations used: COPD, chronic obstructive pulmonary disease; BTS, British Thoracic Society classification; GOLD, Global Obstructive Lung Disease classification; SPLF, Société de Pneumonologie de Langue Française classification.

one country to another, but data interpretation must be done carefully. First, the International Classification of Diseases (ICD) has evolved with time, and the underlying classification or codes used for estimating mortality (for example, Hurd et al.[78] included codes 495 and
496 corresponding to asthma) are never similar from one study to another. Overall, mortality estimates have increased with time. However, increases in COPD mortality and features related to coding of mortality may both be involved in this increase, with relative parts 
Table 4 COPD exacerbations ${ }^{a}$

\begin{tabular}{|c|c|c|c|c|}
\hline $\begin{array}{l}\text { Exacerbation definition group } \\
\left.\text { (study type }^{b}\right)\end{array}$ & Country (sample size) & $\begin{array}{l}\text { Classification } \\
\text { (stage of COPD) }\end{array}$ & $\begin{array}{l}\text { Mean number of } \\
\text { exacerbations per patient } \\
\text { and per yearc }\end{array}$ & Treatment \\
\hline \multicolumn{5}{|l|}{ Treatment } \\
\hline \multirow[t]{2}{*}{ Burge et al., $2003[58]^{d}$ (CT) } & United Kingdom (524) & GOLD (2 or 3) & $1.6-1.7$ & Placebo \\
\hline & & & $1.1-1.4$ & Fluticasone propionate \\
\hline \multirow[t]{4}{*}{ Calverley et al., 2003 [59] (CT) } & 25 countries $(1,974)$ & GOLD (2 or 3) & 1.3 & Placebo \\
\hline & & & 1.0 & Salmeterol \\
\hline & & & 1.0 & Fluticasone \\
\hline & & & 1.0 & Salmeterol and fluticasone \\
\hline \multirow[t]{4}{*}{ Jones et al., $2003[60]^{d}(C T)$} & United Kingdom (751) & GOLD (1 or 2) & 1.0 & Placebo \\
\hline & & & 0.7 & Fluticasone \\
\hline & & GOLD (3 or 4) & 1.7 & Placebo \\
\hline & & & 1.5 & Fluticasone \\
\hline Andersson et al., 2002 [61] (CT) & Sweden (191) & GOLD/BTS & 1.2 & \\
\hline \multirow[t]{2}{*}{ Burge et al., $2000[62]^{d}(C T)$} & United Kingdom (751) & GOLD (2 or 3$)$ & $1.9(2.6)$ & Placebo \\
\hline & & & $1.4(1.9)$ & Fluticasone \\
\hline \multicolumn{5}{|l|}{ Symptoms } \\
\hline Effing et al., 2009 [63] (CT) & Netherlands (142) & GOLD (2 or 3$)$ & $3.5(2.7)$ & \\
\hline \multirow[t]{2}{*}{ Worth et al., 2009 [64] $]^{\mathrm{e}}(\mathrm{CT})$} & Germany (220) & GOLD (3 or 4) & 0.9 & Placebo \\
\hline & & & 0.4 & Cineole \\
\hline \multirow[t]{3}{*}{ Schermer et al., 2009 [65] (CT) } & Netherlands (286) & GOLD (1-3) & 0.7 & Placebo \\
\hline & & & 0.9 & Fluticasone \\
\hline & & & 1.0 & $\mathrm{~N}$-acetylcysteine \\
\hline \multirow[t]{4}{*}{ O'Reilly et al., 2006 [66] (OS) } & United Kingdom (309) & GOLD (1 or 2) & $2.2[1.9-2.7]$ & Symptom-defined \\
\hline & & & $2.3[2.0-2.8]$ & Healthcare-defined \\
\hline & & GOLD (3 or 4) & $2.5[2.1-2.9]$ & Symptom-defined \\
\hline & & & $3.2[2.8-3.7]$ & Healthcare-defined \\
\hline Wilkinson et al., 2006 [67] (OS) & United Kingdom (74) & GOLD (2 or 3$)$ & $2.5\{1.3-3.8\}$ & \\
\hline Donaldson et al., 2003 [68] (OS) & United Kingdom (132) & GOLD (2 or 4) & $2.5\{1.3-3.9\}$ & \\
\hline Seemungal et al., 2000 [69] (OS) & United Kingdom (101) & GOLD (2 or 4) & $2.4\{1.3-3.8\}$ & \\
\hline \multicolumn{5}{|l|}{ Treatment and symptoms } \\
\hline \multirow[t]{2}{*}{ Seemungal et al., 2008 [70] (CT) } & United Kingdom (109) & GOLD (2 or 3$)$ & 2.0 & Placebo \\
\hline & & & 1.0 & Erythromycin \\
\hline \multirow[t]{2}{*}{ Tashkin et al., 2008 [71] (CT) } & 37 countries $(5,993)$ & GOLD (2-4) & 0.8 & Placebo \\
\hline & & & 0.7 & Tiotropium \\
\hline \multirow[t]{2}{*}{ Calverley et al., 2008 [72] (CT) } & 11 countries (911) & GOLD (2 or 3$)$ & 1.0 & Placebo \\
\hline & & & 0.6 & Mometasone furoate \\
\hline \multirow[t]{2}{*}{ Wedzicha et al., 2008 [73] (CT) } & 20 countries $(1,323)$ & GOLD (3 or 4) & 1.3 & SFC \\
\hline & & & 1.3 & Tiotropium \\
\hline \multirow[t]{4}{*}{ Dusser et al., 2006 [74] (CT) } & France $(1,010)$ & GOLD (1 or 2$)$ & 2.0 & Placebo \\
\hline & & & 1.2 & Tiotropium \\
\hline & & GOLD (3 or 4) & 1.8 & Placebo \\
\hline & & & 2.7 & Tiotropium \\
\hline \multirow[t]{4}{*}{ Soler-Cataluña et al., 2005 [55] (OS) } & Spain (304) & GOLD (1) & $(75,25,00)^{f}$ & \\
\hline & & GOLD (2) & $(60,35,05)^{f}$ & \\
\hline & & GOLD (3) & $(56,32,12)^{f}$ & \\
\hline & & GOLD (4) & $(34,40,26)^{f}$ & \\
\hline \multirow[t]{2}{*}{ Oostenbrink et al., 2004 [75] (CT) } & Netherlands and Belgium (519) & GOLD (1-4) & $1.0(0.1)$ & Placebo \\
\hline & & & $0.7(0.1)$ & Fluticasone \\
\hline
\end{tabular}


Table 4 COPD exacerbations ${ }^{a}$ (Continued)

\begin{tabular}{|c|c|c|c|c|}
\hline \multirow[t]{3}{*}{ Brusasco et al., 2003 [76] (CT) } & 18 countries $(1,207)$ & GOLD (2 or 3$)$ & 1.5 & Placebo \\
\hline & & & 1.2 & Salmeterol \\
\hline & & & 1.1 & Tiotropium \\
\hline \multicolumn{5}{|l|}{ Model } \\
\hline \multirow[t]{4}{*}{ Borg et al., 2004 [77] (M) } & Netherlands & GOLD (1) & $(0.05,0.07,0.01)^{g}$ & \\
\hline & & GOLD (2) & $(1.01,1.31,0.14)^{\mathrm{g}}$ & \\
\hline & & GOLD (3) & $(1.06,1.45,0.17)^{\mathrm{g}}$ & \\
\hline & & GOLD (4) & $(1.47,1.72,0.33)^{\mathrm{g}}$ & \\
\hline \multicolumn{5}{|l|}{ Not defined } \\
\hline \multirow[t]{4}{*}{ Detournay et al., 2004 [53] (OS) } & France (255) & Moderate & 1.7 & \\
\hline & & Moderate to & 1.5 & \\
\hline & & severe & & \\
\hline & & Severe & 2.0 & \\
\hline \multicolumn{5}{|c|}{ 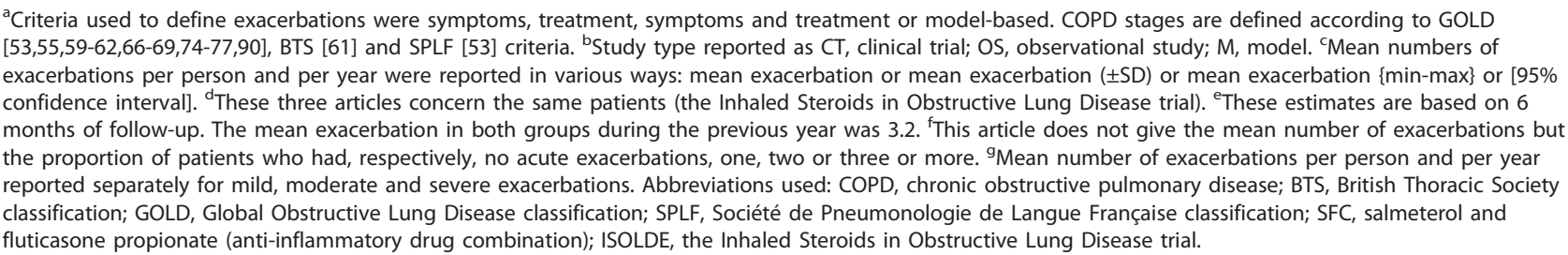 } \\
\hline
\end{tabular}

Table 5 COPD age-standardized mortality rates ${ }^{a}$

\begin{tabular}{|c|c|c|c|c|c|c|c|}
\hline \multirow[b]{2}{*}{ Population } & \multirow[b]{2}{*}{ Country } & \multirow[b]{2}{*}{ Year(s) } & \multirow[b]{2}{*}{ Age (yr) } & \multicolumn{3}{|c|}{$\begin{array}{c}\text { Annual mortality rate } \\
\text { (per } 100,000 \text { inhabitants) }\end{array}$} & \multirow[b]{2}{*}{ Classification codes used } \\
\hline & & & & Global & Male & Female & \\
\hline \multicolumn{8}{|l|}{ General population } \\
\hline \multirow[t]{21}{*}{ Eurostat $^{\mathrm{b}, \mathrm{c}}[10]$} & Austria & 2007 & & 19.4 & 30.8 & 12.1 & ICD 10 (J40-J44, J47) \\
\hline & Bulgaria & & & 15.8 & 26.7 & 07.9 & \\
\hline & Cyprus & & & 09.3 & 15.5 & 04.7 & \\
\hline & Czech Republic & & & 14.7 & 24.1 & 08.5 & \\
\hline & Estonia & & & 10.7 & 24.2 & 04.4 & \\
\hline & Finland & & & 12.9 & 25.3 & 05.4 & \\
\hline & France & & & 07.2 & 12.5 & 03.8 & \\
\hline & Germany & & & 16.3 & 24.9 & 10.8 & \\
\hline & Greece $^{d}$ & & & 10.9 & 14.8 & 07.9 & \\
\hline & Hungary & & & 36.1 & 56.5 & 23.6 & \\
\hline & Lithuania & & & 22.4 & 49.0 & 08.5 & \\
\hline & Latvia & & & 09.7 & 22.4 & 03.0 & \\
\hline & Malta & & & 16.0 & 35.4 & 02.7 & \\
\hline & Netherlands & & & 26.0 & 39.6 & 18.7 & \\
\hline & Poland & & & 16.8 & 32.0 & 07.8 & \\
\hline & Romania & & & 20.6 & 33.8 & 11.4 & \\
\hline & Spain & & & 18.4 & 37.1 & 06.1 & \\
\hline & Sweden & & & 15.1 & 17.6 & 13.6 & \\
\hline & Slovakia & & & 12.8 & 24.5 & 05.9 & \\
\hline & Slovenia & & & 13.2 & 23.4 & 07.5 & \\
\hline & United Kingdom & & & 28.4 & 35.5 & 23.7 & \\
\hline \multirow[t]{4}{*}{ Hurd et al., 2000 [78] } & Austria & 1997 & $35-74$ & & 32 & 6 & ICD 9 (490-496) \\
\hline & Bulgaria & 1994 & & & 38 & 8 & \\
\hline & France & 1995 & & & 26 & 5 & \\
\hline & Germany & 1997 & & & 28 & 11 & \\
\hline
\end{tabular}


Table 5 COPD age-standardized mortality rates ${ }^{a}$ (Continued)

\begin{tabular}{|c|c|c|c|c|c|c|c|}
\hline & Greece & 1996 & & & 12 & 1 & \\
\hline & Hungary & 1995 & & & 75 & 23 & \\
\hline & Italy & 1993 & & & 30 & 4 & \\
\hline & Netherlands & 1995 & & & 43 & 15 & \\
\hline & Poland & 1996 & & & 43 & 8 & \\
\hline & Portugal & 1996 & & & 38 & 7 & \\
\hline & Romania & 1996 & & & 61 & 18 & \\
\hline & Spain & 1995 & & & 45 & 6 & \\
\hline & Sweden & 1996 & & & 22 & 12 & \\
\hline & United Kingdom & 1997 & & & 48 & 31 & \\
\hline \multirow[t]{16}{*}{ Siafakas et al., 1995 [45] } & Austria & 1988-1991 & NS & & 18 & 6 & ICD 9 (490-493) \\
\hline & Belgium & & & & 28 & 9 & \\
\hline & Bulgaria & & & & 11 & 6 & \\
\hline & Denmark & & & & 34 & 20 & \\
\hline & Finland & & & & 22 & 4 & \\
\hline & France & & & & 10 & 3 & \\
\hline & Greece & & & & 03 & 2 & \\
\hline & Hungary & & & & 40 & 16 & \\
\hline & Italy & & & & 25 & 8 & \\
\hline & Netherlands & & & & 20 & 5 & \\
\hline & Poland & & & & 29 & 8 & \\
\hline & Portugal & & & & 14 & 5 & \\
\hline & Romania & & & & 20 & 12 & \\
\hline & Spain & & & & 10 & 3 & \\
\hline & Sweden & & & & 11 & 5 & \\
\hline & United Kingdom & & & & 12 & 6 & \\
\hline \multicolumn{8}{|l|}{ Hospital population ${ }^{\mathrm{e}}$} \\
\hline Gudmundsson et al., 2006 [81] & SweNorFin ${ }^{g}$ & 2002 & $72.1 \pm 8.7$ & 293 & & & ICD $10(J 40-J 47)$ \\
\hline Groeneweger et al., 2003 $[79]$ & Netherlands & 2001 & $70.6 \pm 8.5$ & 230 & & & COPD-ATS \\
\hline Almagro et al., 2002' [80] & Spain & 1999 & $72.0 \pm 9$ & 220 & & & $\mathrm{COPD}^{\mathrm{j}}$ \\
\hline
\end{tabular}

${ }^{a}$ Age was reported in various ways: mean age $( \pm S D)$, or age range, min-max. ${ }^{b}$ Not all European countries have COPD mortality data for 2007 in the Eurostat database. 'Total population (all ages). ${ }^{\mathrm{d}}$ Greece does not have mortality data for asthma in 2007; these estimates correspond to J40-J47 and not to J40-J44, J47. ${ }^{\mathrm{e}}$ Mortality rates in inpatients are of course not age-standardized but represent the number of deaths per 100,000 inhabitants. ${ }^{\mathrm{f}}$ Mortality rates at 1 year for stages GOLD 1 and GOLD 2, GOLD 3, and GOLD 4 are 3.6, 6.9, and 13.7, respectively. ${ }^{9}$ This study concerned Sweden, Norway and Finland. ${ }^{\mathrm{h}}$ Mortality rate at 6 months was 18 . 'Mortality rates at 6 and 24 months were, respectively, 13.4 and 35.6 . ${ }^{\mathrm{j}}$ Clinical diagnosis of COPD and forced spirometry at discharge showing FEV $1<70 \%$ of the reference value and $\mathrm{FEV}_{1} / \mathrm{FVC}$ ratio $<70 \%$. Abbreviations used: ICD, International Classification of Diseases. COPD-ATS, chronic obstructive pulmonary disease as defined by the American Thoracic Society; NS, not specified; GOLD, Global Obstructive Lung Disease classification stage; FEV 1 , maximum expiratory volume in 1 second; FVC, forced vital capacity.

hardly quantifiable. At present, the fairest comparison between countries should be made with 2007 European COPD-related mortality estimates issued by Eurostat [10]. The estimates ranged from 7.2 per 100,000 inhabitants in France to 36.1 per 100,000 inhabitants in Hungary, and mortality was between 1.3 (Sweden) and 13 (Malta) times higher in men than in women. Mortality estimates among hospital inpatients are high, as expected, at around $25 \%[79,80]$ or even higher in patients with comorbidities [81]. The mortality of hospitalized patients with COPD increases with the number of exacerbations: In the study by Soler-Cataluña et al. [55], patients with 0,1 or 2 and 3 or more acute COPD exacerbations per year had 36-month survival probabilities of $0.86,0.70$ and 0.42 , respectively.

\section{Discussion}

This study describes the variability of reported COPD epidemiological data in European countries. Although the search of documents was limited to the WOS and Eurostat databases, the collected information was sufficient to outline how international standardization of research methodology has evolved over time and has contributed to estimates of better quality. In that regard, whereas documents not included in the present study, such as unpublished information, might be available through national health surveys or other initiatives, their additional value to this study is likely to be low.

As shown, one of the main reasons for the variability of the reported epidemiological estimates is the use of different methods by different authors, hindering valid 
comparisons. For example, prevalence estimates were based on a wide variety of methods (for example, symptoms, physician reports, spirometry, models), different populations (for example, general population, hospital inpatients), different age distributions and different definitions of COPD. Studies based on a small number of patients and on interviews (symptoms or physician reports) are not as reliable as larger studies based on spirometry. Methods based on symptoms are neither specific nor sensitive for the diagnosis of COPD. The use of a screening questionnaire (and questionnaires may also vary from one study to another) does not allow thorough investigation of the specific characteristics of the patients, and the lack of functional investigations means that questions on progression from cough and sputum production to airflow obstruction remain unanswered [15]. The same applies to studies based on physician reports. Thus, in a study of a given general population sample, the estimated prevalence is, respectively, $5.6 \%$ and $26.1 \%$, depending on whether one uses physician reports or spirometry [19]. The use of different severity scales is another important source of heterogeneity [19]. For example, among 212 patients included in the Obstructive Lung Disease in Northern Sweden surveys, 179 had COPD in the BTS classification, whereas all had COPD on the basis of the GOLD 2006 criteria, including patients with $\mathrm{FEV}_{1} \geq 80 \%$ of the predicted level (mild form) [49]. Because of these methodological problems and imprecise definitions, the terms chronic bronchitis and chronic obstructive pulmonary disease often were not differentiated in the past. However, these methodological limitations do not entirely explain the observed epidemiological variability. Other factors such as smoking and age probably contribute to the observed variability. A recent study considering COPD patients randomly selected from registers in a Swedish region indicated that only $59 \%$ had an initial diagnosis that involved spirometry [82], and in fact only longitudinal studies of young populations could allow early diagnosis and refine our knowledge of the natural history of COPD. In the recent largest international study on COPD, the BOLD study, prevalence data based on spirometry according to GOLD guidelines were collected at 12 sites in different countries, 5 of which were located in Europe [8]. Interestingly, these prevalence estimates are within the same range as those reported in the PLATINO study of five Latin American countries [9]. These results likely reflect the benefits of the international standardization of methodology. Nevertheless, the BOLD study reported significant differences across the different sites $(P<0.0001)$, but the authors underlined the danger of extrapolating data from such sites (a pool of about 150,000 people) to national populations. Therefore, the present national prevalence estimates that may be twice those from one European country to another (Table 1) should still be considered with caution.

As observed with regard to prevalence, a large epidemiological variability is observed with respect to COPD severity, but our study indicates that severity is the parameter for which recent standardization has resulted in the best improvement of estimates. Besides, severity is a very active research domain. In recent years, several composite scores, such as the BODE index (body mass index, airflow obstruction, dyspnea and exercise capacity), ADO index (age, dyspnea and airflow obstruction) or the DOSE index (dyspnea, airflow obstruction, smoking status and exacerbation frequency) [83,84], have been proposed for grading patients' disease severity. At present, the GOLD severity scale is the international standard, and our results indicate that recent estimates from the international studies based on this classification generally represent relatively low differences in the distribution of severity from one country to another within a given type of population.

This situation contrasts with the reported data on exacerbations for which the GOLD initiative did not recommend methodological guidelines. Unsurprisingly, exacerbation data clearly indicate that severe COPD is associated with more frequent and more severe exacerbations, but estimates of the frequency of exacerbations depend largely on the definition used $[59,66,76]$. Exacerbations are variously defined as a complex of respiratory symptoms or as a complex of respiratory symptoms requiring steroid or antibiotic treatment (Table 4). The influence of age and smoking status on exacerbations is poorly documented. The main COPD management objective is currently to prevent exacerbations. Most estimates concerning exacerbations come from therapeutic trials, which focus on selected populations and in which the frequency of exacerbations is used to judge treatment efficacy. As underlined by Aaron et al. [85], standardizing counts, analyses and method of reporting exacerbations are of major importance for a fair evaluation of treatments tested in randomized controlled trials.

Although several studies have reported COPD mortality data [45,78-81], the mortality data in the general population issued by Eurostat are those allowing the most standardized comparison between countries. The ICD is an international standard for categorizing mortality data, but the reliability of mortality estimates is undermined by problems of coding [86]. In addition, since some researchers think that there is a considerable overlap between asthma and COPD in adults, some COPD mortality estimates may be overestimated. Conversely, COPD mortality is also underreported [87], and causes of death remain to be standardized among patients with several comorbidities [16]. It may be difficult to get a 
great deal of consistency, because patients with COPD often do not die as a result of acute exacerbations of COPD or respiratory failure. More often they die as a result of cardiovascular causes, cancer, pneumonia and other related conditions. It can be challenging and difficult to decide which ICD code to use in recording the death certificate. More work is needed to come up with a realistic method of assessing the mortality rate in COPD. Finally, observed variations in COPD mortality rates across countries include variations in performance of the local healthcare systems with respect to COPD patient management, but indicators permitting such comparisons in specific settings are lacking.

The difficulties in comparing COPD studies outlined in this review can be attributed to two distinct reasons. First, the methodological bases may vary from one study to another, such as the definition of COPD. Nevertheless, our study also shows that efforts to establish congruence among COPD definitions and study methods are underway. Second, regardless of the methodology used for performing the study, the method of reporting results, such as exacerbation data, may vary from one report to another. This may also concern the reporting of important features related to the disease, such as smoking history. Smoking consumption (patients may be categorized in arbitrary classes of pack-year consumption) was used in some studies, whereas others used a three smoking status categorization (never smoker, former smoker, current smoker). There are current guidelines for reporting research, but they are based on the methodological type of the studies [88]. Our study strongly suggests that establishing reporting guidelines dedicated to COPD studies may constitute a major contribution to enhancing the value of COPD research and management by facilitating comparisons between studies.

\section{Conclusions}

COPD is a major public health problem [89]. The wide range of prevalence, severity and mortality estimates across European countries cannot possibly correspond to real differences, but it remains difficult to assess the part of this heterogeneity due to methodological issues and the part of this heterogeneity due to countries' characteristics, such as differences in national smoking exposure. National prevalence estimates are still far from perfect, impairing fair comparisons from one country to another. The present study outlines that with time, congruence of COPD definitions, especially in terms of severity classification, and methodological standardization have resulted in more comparable epidemiological estimates, but much remains to be made in terms of exacerbation data. Many international efforts have been made to develop common rules for coding mortality data, but they concern all diseases, and potential improvements of COPD mortality data are likely to poorly depend on specific COPD programs. Efforts to establish common standardized COPD definitions and study methods are underway, and researchers are encouraged to do more to better assess the disease and the relative effectiveness of methods of patient management in different European Union member states. In that regard, the establishment of international guidelines for reporting research on COPD may constitute an important contribution. Indeed, the present review strongly supports the use of commonly agreed guidelines for bringing more uniformity to the findings reported in future studies. Our results emphasize the need for scientists and investigators to work harder at adopting common guidelines that may be imperfect but nevertheless acceptable, so that the epidemiological database can be richer, the burden of the disease can be better defined and the response of patients with COPD to treatment can be better evaluated.

\section{Additional material}

Additional File 1: Figure A1. Chronic obstructive pulmonary disease (COPD) prevalence data. A graph of the prevalence estimates presented in Table 1.

Additional File 2: Figure A2. COPD severity data. A graph of the severity data presented in Table 2.

Additional File 3: Figure A3. COPD age-standardized mortality rates (number per 100,000). A graph of age-standardized mortality data presented in Table 5

\section{Acknowledgements}

This work was supported by a grant from Office Français de Prévention du Tabagisme (OFT) and Association CARDIF-L'Assistance Respiratoire. Neither organization had any control over the design, analysis or reporting of the research.

\section{Author details}

${ }^{1}$ INSERM, U707, F-75012 Paris, France. ' $U P M C$, Université de Paris 06, UMR S 707, F-75012 Paris, France. ${ }^{3}$ AP-HP, Hôpital Saint Antoine, Service de Pneumologie, F-75012 Paris, France. ${ }^{4}$ AP-HP, Hôpital Saint Antoine, Unité de Santé Publique, F-75012 Paris, France.

\section{Authors' contributions}

KA, CC and GH were responsible for the study's conception, design and data analysis as well as the drafting of the manuscript. KA also performed data collection.

\section{Competing interests}

The authors declare that they have no competing interests.

Received: 30 November 2010 Accepted: 18 January 2011 Published: 18 January 2011

\section{References}

1. Celli BR, MacNee W: Standards for the diagnosis and treatment of patients with COPD: a summary of the ATS/ERS position paper. Eur Respir J 2004, 23:932-946.

2. Hurd S, Pauwels R: Global Initiative for Chronic Obstructive Lung Diseases (GOLD). Pulm Pharmacol Ther 2002, 15:353-355. 
3. Mathers $C D$, Loncar $D$ : Projections of global mortality and burden of disease from 2002 to 2030. PLoS Med 2006, 3:e442.

4. Jemal $A$, Ward E, Hao $Y$, Thun M: Trends in the leading causes of death in the United States, 1970-2002. JAMA 2005, 294:1255-1259.

5. Murray CJ, Lopez AD: Alternative projections of mortality and disability by cause 1990-2020: Global Burden of Disease Study. Lancet 1997, 349:1498-1504.

6. Bellamy D, Bouchard J, Henrichsen S, Johansson G, Langhammer A, Reid J, van Weel C, Buist S: International Primary Care Respiratory Group (IPCRG) Guidelines: management of chronic obstructive pulmonary disease (COPD). Prim Care Respir J 2006, 15:48-57.

7. Société de Pneumologie de Langue Française: [Recommendations of the Francophone Society of Pneumology for pulmonary rehabilitation in COPD] [Article in French]. Rev Mal Respir 2005, 22:696-704.

8. Buist AS, McBurnie MA, Vollmer WM, Gillespie S, Burney P, Mannino DM, Menezes AM, Sullivan SD, Lee TA, Weiss KB, Jensen RL, Marks GB, Gulsvik A, Nizankowska-Mogilnicka E: International variation in the prevalence of COPD (the BOLD Study): a population-based prevalence study. Lancet 2007, 370:741-750

9. Menezes AM, Perez-Padilla R, Jardim JR, Muiño A, Lopez MV, Valdivia G, Montes de Oca M, Talamo C, Hallal PC, Victora CG, PLATINO team: Chronic obstructive pulmonary disease in five Latin American cities (the PLATINO study): a prevalence study. Lancet 2005, 366:1875-1881.

10. Eurostat: Causes of death: Standardised death rate (per 100,000 inhabitants) (Annual Data). [http://nui.epp.eurostat.ec.europa.eu/nui/show. do?dataset=hlth_cd_asdr\&lang=en].

11. Jaén A, Ferrer A, Ormaza I, Rué M, Domingo C, Marín A: [Prevalence of chronic bronchitis, asthma and airflow limitation in an urban-industrial area of Catalonia] [Article in Spanish]. Arch Bronconeumol 1999, 35:122-128.

12. Marco Jordán L, Martín Berra JC, Corres Iñigo M, Luque Díez R, Zubillaga Garmendia G: [Chronic obstructive lung disease in the general population. An epidemiologic study performed in Guipúzcoa] [Article in Spanish]. Arch Bronconeumol 1998, 34:23-27.

13. Brotons B, Pérez JA, Sánchez-Toril F, Soriano S, Hernández J, Belenguer JL: [The prevalence of chronic obstructive pulmonary disease and asthma: a cross-sectional study] [Article in Spanish]. Arch Bronconeumol 1994, 30:149-152.

14. Piperno D, Bart F, Serrier P, Zureik M, Finkielsztejn L: [General practice patients at risk of chronic obstructive pulmonary disease: epidemiologic survey of 3,411 patients] [Article in French]. Presse Med 2005, 34:1617-1622.

15. Cerveri I, Accordini S, Corsico A, Zoia MC, Carrozzi L, Cazzoletti L, Beccaria M, Marinoni A, Viegi G, de Marco R: Chronic cough and phlegm in young adults. Eur Respir J 2003, 22:413-417.

16. Huchon GJ, Vergnenegre A, Neukirch F, Brami G, Roche N, Preux PM: Chronic bronchitis among French adults: high prevalence and underdiagnosis. Eur Respir J 2002, 20:806-812.

17. Cerveri I, Accordini S, Verlato G, Corsico A, Zoia MC, Casali L, Burney P, de Marco R: Variations in the prevalence across countries of chronic bronchitis and smoking habits in young adults. Eur Respir J 2001, 18:85-92.

18. Cazzola M, Bettoncelli G, Sessa E, Cricelli C: Primary care of the patient with chronic obstructive pulmonary disease in Italy. Respir Med 2009, 103:582-588.

19. Schirnhofer L, Lamprecht B, Vollmer WM, Allison MJ, Studnicka M, Jensen RL, Buist AS: COPD prevalence in Salzburg, Austria: results from the Burden of Obstructive Lung Disease (BOLD) Study. Chest 2007, 131:29-36.

20. Montnemery R, Nihlen $U$, Andersson M, Greiff $L$, Johannisson A, Nyberg $P$, Persson CG, Lofdahl CG: Obstructive airways diseases, smoking and use of inhaled corticosteroids in southern Sweden in 1992 and 2000. Int J Tuberc Lung Dis 2006, 10:490-498.

21. Hedman J, Kaprio J, Poussa T, Nieminen MM: Prevalence of asthma, aspirin intolerance, nasal polyposis and chronic obstructive pulmonary disease in a population-based study. Int J Epidemiol 1999, 28:717-722.

22. Montnemery $P$, Adelroth $E$, Heuman $K$, Johannisson A, Johansson SA, Lindholm LH, Lundback B, Lofdahl CG: Prevalence of obstructive lung diseases and respiratory symptoms in southern Sweden. Respir Med 1998, 92:1337-1345.

23. Lundback B, Nystrom L, Rosenhall L, Stjernberg N: Obstructive lung disease in northern Sweden: respiratory symptoms assessed in a postal survey. Eur Respir J 1991, 4:257-266.
24. Miravitlles M, Soriano JB, Garcia-Rio F, Munoz L, Duran-Tauleria E, Sanchez G, Sobradillo V, Ancochea J: Prevalence of COPD in Spain: impact of undiagnosed COPD on quality of life and daily life activities. Thorax 2009, 64:863-868.

25. Van Durme YM, Verhamme KM, Stijnen T, van Rooij FJ, Van Pottelberge GR, Hofman A, Joos GF, Stricker BH, Brusselle GG: Prevalence, incidence, and lifetime risk for the development of COPD in the elderly: the Rotterdam study. Chest 2009, 135:368-377.

26. Hansen JG, Pedersen L, Overvad K, Omland $\varnothing$, Jensen HK, Sørensen HT: The prevalence of chronic obstructive pulmonary disease among Danes aged 45-84 years: population-based study. COPD 2008, 5:347-352.

27. Bednarek M, Maciejewski J, Wozniak M, Kuca P, Zielinski J: Prevalence, severity and underdiagnosis of COPD in the primary care setting. Thorax 2008, 63:402-407.

28. Roche N, Dalmay F, Perez T, Kuntz C, Vergnenegre A, Neukirch F, Giordanella JP, Huchon G: Impact of chronic airflow obstruction in a working population. Eur Respir J 2008, 31:1227-1233.

29. Shahab L, Jarvis MJ, Britton J, West R: Prevalence, diagnosis and relation to tobacco dependence of chronic obstructive pulmonary disease in a nationally representative population sample. Thorax 2006, 61:1043-1047.

30. Stavem K, Sandvik L, Erikssen J: Can Global Initiative for Chronic Obstructive Lung Disease stage 0 provide prognostic information on long-term mortality in men? Chest 2006, 130:318-325.

31. Sichletidis L, Tsiotsios I, Gavriilidis A, Chloros D, Kottakis I, Daskalopoulou E, Konstantinidis T: Prevalence of chronic obstructive pulmonary disease and rhinitis in northern Greece. Respiration 2005, 72:270-277.

32. Murtagh E, Heaney L, Gingles J, Shepherd R, Kee F, Patterson C, MacMahon J: Prevalence of obstructive lung disease in a general population sample: the NICECOPD study. Eur J Epidemiol 2005, 20:443-453.

33. Tzanakis N, Anagnostopoulou U, Filaditaki V, Christaki P, Siafakas N: Prevalence of COPD in Greece. Chest 2004, 125:892-900.

34. Hasselgren M, Arne M, Lindahl A, Janson S, Lundback B: Estimated prevalences of respiratory symptoms, asthma and chronic obstructive pulmonary disease related to detection rate in primary health care. Scand J Prim Health Care 2001, 19:54-57.

35. Peña VS, Miravitlles M, Gabriel R, Jiménez-Ruiz CA, Villasante C, Masa JF, Viejo JL, Fernández-Fau L: Geographic variations in prevalence and underdiagnosis of COPD: results of the IBERPOC multicentre epidemiological study. Chest 2000, 118:981-989.

36. Viegi G, Pedreschi M, Pistelli F, Di Pede F, Baldacci S, Carrozzi L, Giuntini C: Prevalence of airways obstruction in a general population: European Respiratory Society vs American Thoracic Society definition. Chest 2000, 117(Suppl 2):339-345.

37. Dickinson JA, Meaker M, Searle M, Ratcliffe G: Screening older patients for obstructive airways disease in a semi-rural practice. Thorax 1999. 54:501-505.

38. Renwick DS, Connolly MJ: Prevalence and treatment of chronic airways obstruction in adults over the age of 45. Thorax 1996, 51:164-168.

39. Bakke PS, Baste V, Hanoa R, Gulsvik A: Prevalence of obstructive lung disease in a general population: relation to occupational title and exposure to some airborne agents. Thorax 1991, 46:863-870.

40. Peabody JW, Schau B, Lopez-Vidriero M, Vestbo J, Wade S, lqbal A: COPD: a prevalence estimation model. Respirology 2005, 10:594-602.

41. Feenstra TL, van Genugten ML, Hoogenveen RT, Wouters EF, Rutten-van Molken MP: The impact of aging and smoking on the future burden of chronic obstructive pulmonary disease: a model analysis in the Netherlands. Am J Respir Crit Care Med 2001, 164:590-596.

42. Stang P, Lydick E, Silberman C, Kempel A, Keating ET: The prevalence of COPD: using smoking rates to estimate disease frequency in the general population. Chest 2000, 117(Suppl 2):354-359.

43. American Thoracic Society: Standards for the diagnosis and care of patients with chronic obstructive pulmonary disease. Am J Respir Crit Care Med 1995, 152:S77-S121.

44. The COPD Guidelines Group of the Standards of Care Committee of the BTS: BTS guidelines for the management of chronic obstructive pulmonary disease. Thorax 1997, 52(Suppl 5):1-28.

45. Siafakas NM, Vermeire P, Pride NB, Paoletti P, Gibson J, Howard P, Yernault JC, Decramer M, Higenbottam T, Postma DS, Rees J, on behalf of the European Respiratory Society Task Force: Optimal assessment and management of chronic obstructive pulmonary disease (COPD): the European Respiratory Society Task Force. Eur Respir J 1995, 8:1398-1420. 
46. Rabe KF, Hurd S, Anzueto A, Barnes PJ, Buist SA, Calverley P, Fukuchi Y, Jenkins C, Rodriguez-Roisin R, van Weel C, Zielinski J: Global strategy for the diagnosis, management, and prevention of chronic obstructive pulmonary disease: GOLD executive summary. Am J Respir Crit Care Med 2007, 176:532-555

47. Lindberg A, Bjerg-Backlund A, Ronmark E, Larsson LG, Lundback B: Prevalence and underdiagnosis of COPD by disease severity and the attributable fraction of smoking: report from the Obstructive Lung Disease in Northern Sweden Studies. Respir Med 2006, 100:264-272.

48. De Marco R, Accordini S, Cerveri I, Corsico A, Sunyer J, Neukirch F, Kunzli N, Leynaert B, Janson C, Gislason T, Vermeire P, Svanes C, Anto JM, Burney P: An international survey of chronic obstructive pulmonary disease in young adults according to GOLD stages. Thorax 2004, 59:120-125.

49. Jansson SA, Andersson F, Borg S, Ericsson Å, Jönsson E, Lundback B: Costs of COPD in Sweden according to disease severity. Chest 2002, 122:1994-2002.

50. Von Hertzen L, Reunanen A, Impivaara O, Malkia E, Aromaa A: Airway obstruction in relation to symptoms in chronic respiratory disease: a nationally representative population study. Respir Med 2000, 94:356-363.

51. Izquierdo JL, Barcina C, Jimenez J, Munoz M, Leal M: Study of the burden on patients with chronic obstructive pulmonary disease. Int J Clin Pract 2009, 63:87-97.

52. Hoogendoorn M, Feenstra TL, Schermer TR, Hesselink AE, Rutten-van Molken MP: Severity distribution of chronic obstructive pulmonary disease (COPD) in Dutch general practice. Respir Med 2006, 100:83-86.

53. Detournay B, Pribil C, Fournier M, Housset B, Huchon G, Huas D, Godard P, Voinet C, Chanal I, Jourdanne C, Durand-Zaleski I: The SCOPE study: health-care consumption related to patients with chronic obstructive pulmonary disease in France. Value Health 2004, 7:168-174.

54. Soriano JB, Maier WC, Egger P, Visick G, Thakrar B, Sykes J, Pride NB: Recent trends in physician diagnosed COPD in women and men in the UK. Thorax 2000, 55:789-794.

55. Soler-Cataluña JJ, Martínez-García MA, Román Sánchez P, Salcedo E, Navarro M, Ochando R: Severe acute exacerbations and mortality in patients with chronic obstructive pulmonary disease. Thorax 2005, 60:925-931.

56. Tsoumakidou M, Tzanakis N, Voulgaraki O, Mitrouska I, Chrysofakis G, Samiou M, Siafakas NM: Is there any correlation between the ATS, BTS ERS and GOLD COPD's severity scales and the frequency of hospital admissions? Respir Med 2004, 98:178-183.

57. Kornmann O, Beeh KM, Beier J, Geis UP, Ksoll M, Buhl R: Newly diagnosed chronic obstructive pulmonary disease: clinical features and distribution of the novel stages of the Global Initiative for Obstructive Lung Disease. Respiration 2003, 70:67-75.

58. Burge PS, Calverley PM, Jones PW, Spencer S, Anderson JA: Prednisolone response in patients with chronic obstructive pulmonary disease: results from the ISOLDE study. Thorax 2003, 58:654-658.

59. Calverley P, Pauwels R, Vestbo J, Jones P, Pride N, Gulsvik A, Anderson J, Maden $C$ : Combined salmeterol and fluticasone in the treatment of chronic obstructive pulmonary disease: a randomised controlled trial. Lancet 2003, 361:449-456.

60. Jones PW, Willits LR, Burge PS, Calverley PM: Disease severity and the effect of fluticasone propionate on chronic obstructive pulmonary disease exacerbations. Eur Respir J 2003, 21:68-73.

61. Andersson F, Borg S, Jansson SA, Jonsson AC, Ericsson A, Prutz C, Ronmark $E$, Lundback $B$ : The costs of exacerbations in chronic obstructive pulmonary disease (COPD). Respir Med 2002, 96:700-708.

62. Burge PS, Calverley PM, Jones PW, Spencer S, Anderson JA, Maslen TK Randomised, double blind, placebo controlled study of fluticasone propionate in patients with moderate to severe chronic obstructive pulmonary disease: the ISOLDE trial. BMJ 2000, 320:1297-1303.

63. Effing $T$, Kerstjens $H$, van der Valk $P$, Zielhuis $G$, van der Palen J: (Cost)effectiveness of self-treatment of exacerbations on the severity of exacerbations in patients with COPD: the COPE II study. Thorax 2009, 64:956-962.

64. Worth H, Schacher C, Dethlefsen U: Concomitant therapy with Cineole (Eucalyptole) reduces exacerbations in COPD: a placebo-controlled double-blind trial. Respir Res 2009, 10:69.

65. Schermer T, Chavannes N, Dekhuijzen R, Wouters E, Muris J, Akkermans R, van Schayck $\mathrm{O}$, van Weel C: Fluticasone and $\mathrm{N}$-acetylcysteine in primary care patients with COPD or chronic bronchitis. Respir Med 2009, 103:542-551.

66. O'Reilly JF, Williams AE, Holt K, Rice L: Defining COPD exacerbations: impact on estimation of incidence and burden in primary care. Prim Care Respir J 2006, 15:346-353.

67. Wilkinson TM, Donaldson GC, Johnston SL, Openshaw PJ, Wedzicha JA: Respiratory syncytial virus, airway inflammation, and $\mathrm{FEV}_{1}$ decline in patients with chronic obstructive pulmonary disease. Am J Respir Crit Care Med 2006, 173:871-876.

68. Donaldson GC, Seemungal TA, Patel IS, Lloyd-Owen SJ, Wilkinson TM, Wedzicha JA: Longitudinal changes in the nature, severity and frequency of COPD exacerbations. Eur Respir J 2003, 22:931-936.

69. Seemungal TA, Donaldson GC, Bhowmik A, Jeffries DJ, Wedzicha JA: Time course and recovery of exacerbations in patients with chronic obstructive pulmonary disease. Am J Respir Crit Care Med 2000, 161:1608-1613.

70. Seemungal TA, Wilkinson TM, Hurst JR, Perera WR, Sapsford RJ, Wedzicha JA: Long-term erythromycin therapy is associated with decreased chronic obstructive pulmonary disease exacerbations. Am J Respir Crit Care Med 2008, 178:1139-1147.

71. Tashkin DP, Celli B, Senn S, Burkhart D, Kesten S, Menjoge S, Decramer M: A 4-year trial of tiotropium in chronic obstructive pulmonary disease. $N$ Engl J Med 2008, 359:1543-1554.

72. Calverley PM, Rennard S, Nelson HS, Karpel JP, Abbate EH, Stryszak P, Staudinger $\mathrm{H}$ : One-year treatment with mometasone furoate in chronic obstructive pulmonary disease. Respir Res 2008, 9:73.

73. Wedzicha JA, Calverley PM, Seemungal TA, Hagan G, Ansari Z, Stockley RA: The prevention of chronic obstructive pulmonary disease exacerbations by salmeterol/fluticasone propionate or tiotropium bromide. Am J Respir Crit Care Med 2008, 177:19-26.

74. Dusser D, Bravo ML, lacono P: The effect of tiotropium on exacerbations and airflow in patients with COPD. Eur Respir J 2006, 27:547-555

75. Oostenbrink JB, Rutten-van Mölken MP, Al MJ, Van Noord JA, Vincken W: One-year cost-effectiveness of tiotropium versus ipratropium to treat chronic obstructive pulmonary disease. Eur Respir J 2004, 23:241-249.

76. Brusasco V, Hodder R, Miravitlles M, Korducki L, Towse L, Kesten S: Health outcomes following treatment for six months with once daily tiotropium compared with twice daily salmeterol in patients with COPD. Thorax 2003, 58:399-404.

77. Borg S, Ericsson A, Wedzicha J, Gulsvik A, Lundback B, Donaldson GC, Sullivan SD: A computer simulation model of the natural history and economic impact of chronic obstructive pulmonary disease. Value Health 2004, 7:153-167.

78. Hurd S: The impact of COPD on lung health worldwide: epidemiology and incidence. Chest 2000, 117(Suppl):1-4.

79. Groenewegen $\mathrm{KH}$, Schols AM, Wouters EF: Mortality and mortality-related factors after hospitalization for acute exacerbation of COPD. Chest 2003, 124:459-467.

80. Almagro P, Calbo E, Ochoa de Echaguen A, Barreiro B, Quintana S, Heredia JL, Garau J: Mortality after hospitalization for COPD. Chest 2002, 121:1441-1448.

81. Gudmundsson G, Gislason T, Lindberg E, Hallin R, Ulrik CS, Brondum E, Nieminen MM, Aine T, Bakke P, Janson C: Mortality in COPD patients discharged from hospital: the role of treatment and co-morbidity. Respir Res 2006, 7:109.

82. Arne M, Lisspers K, Stallberg B, Boman G, Hedenstrom H, Janson C, Emtner M: How often is diagnosis of COPD confirmed with spirometry? Respir Med 2010, 104:550-556.

83. Jones RC, Donaldson GC, Chavannes NH, Kida K, Dickson-Spillmann M, Harding S, Wedzicha JA, Price D, Hyland ME: Derivation and validation of a composite index of severity in chronic obstructive pulmonary disease: the DOSE Index. Am J Respir Crit Care Med 2009, 180:1189-1195.

84. Puhan MA, Garcia-Aymerich J, Frey M, ter Riet G, Antó JM, Agustí AG, Gómez FP, Rodríguez-Roisín R, Moons KG, Kessels AG, Held U: Expansion of the prognostic assessment of patients with chronic obstructive pulmonary disease: the updated BODE index and the ADO index. Lancet 2009, 374:704-711

85. Aaron SD, Fergusson D, Marks GB, Suissa S, Vandemheen KL, Doucette $S$, Maltais F, Bourbeau JF, Goldstein RS, Balter M, O'Donnell D, Fitzgerald M: Counting, analysing and reporting exacerbations of COPD in randomised controlled trials. Thorax 2008, 63:122-128. 
86. Anderson RN, Minino AM, Hoyert DL, Rosenberg HM: Comparability of cause of death between ICD-9 and ICD-10: preliminary estimates. Natl Vital Stat Rep 2001, 49:1-32

87. Mannino DM, Buist AS, Petty TL, Enright PL, Redd SC: Lung function and mortality in the United States: data from the First National Health and Nutrition Examination Survey follow up study. Thorax 2003, 58:388-393.

88. EQUATOR Network: Library for health research reporting. [http://www. equator-network.org/resource-centre/library-of-health-research-reporting/].

89. Loddenkemper R, Gibson GJ, Sibille Y: The burden of lung disease in Europe. European Lung White Book Lausanne, Switzerland: ERS Ltd; 2003.

90. Burney $P$, Suissa $S$, Soriano JB, Vollmer WM, Viegi G, Sullivan SD, Fabbri LM Sin DD, Ernst P, Coultas D, Bourbeau J, Mapel DW, Weiss K, McLaughlin T, Price D, Sturkenboom MC, Taylor R, Hagan GW: The

pharmacoepidemiology of COPD: recent advances and methodological discussion. Eur Respir J 2003, 22(Suppl 43):41s-44s.

\section{Pre-publication history}

The pre-publication history for this paper can be accessed here: http://www.biomedcentral.com/1741-7015/9/7/prepub

doi:10.1186/1741-7015-9-7

Cite this article as: Atsou et al: Variability of the chronic obstructive pulmonary disease key epidemiological data in Europe: systematic review. BMC Medicine 2011 9:7.

\section{Submit your next manuscript to BioMed Central} and take full advantage of:

- Convenient online submission

- Thorough peer review

- No space constraints or color figure charges

- Immediate publication on acceptance

- Inclusion in PubMed, CAS, Scopus and Google Scholar

- Research which is freely available for redistribution

Submit your manuscript at www.biomedcentral.com/submit 